\title{
Identification of AICP as a GluN2C-Selective $N$-Methyl-D-Aspartate Receptor Superagonist at the GluN1 Glycine Site ${ }^{\mathrm{S}}$
}

\author{
Maja Jessen, Kristen Frederiksen, Feng Yi, Rasmus P. Clausen, Kasper B. Hansen, \\ Hans Bräuner-Osborne, Paul Kilburn, and Anders Damholt ${ }^{1}$
}

\begin{abstract}
Department of Molecular Screening, H. Lundbeck A/S, Valby, Denmark (M.J., K.F., A.D.); Department of Drug Design and Pharmacology, University of Copenhagen, Copenhagen, Denmark (M.J., R.P.C., H.B.-O.); Department of Medicinal Chemistry 1, H. Lundbeck A/S, Valby, Denmark (P.K.); Department of Biomedical and Pharmaceutical Sciences, University of Montana, Missoula, Montana (F.Y., K.B.H.)
\end{abstract}

Received March 31, 2017; accepted June 1, 2017

\begin{abstract}
$\mathrm{N}$-methyl-D-aspartate (NMDA)-type ionotropic glutamate receptors mediate excitatory neurotransmission in the central nervous system and are critically involved in brain function. NMDA receptors are also implicated in psychiatric and neurological disorders and have received considerable attention as therapeutic targets. In this regard, administration of $D$-cycloserine (DCS), which is a glycine site NMDA receptor agonist, can enhance extinction of conditioned fear responses. The intriguing behavioral effects of DCS have been linked to its unique pharmacological profile among NMDA receptor subtypes (GluN1/2A-D), in which DCS is a superagonist at GluN2Ccontaining receptors compared with glycine and a partial agonist at GluN2B-containing receptors. Here, we identify (R)-2-amino-3-(4-(2-ethylphenyl)-1H-indole-2-carboxamido)propanoic acid (AICP) as a glycine site agonist with unique GluN2dependent differences in agonist efficacy at recombinant
\end{abstract}

\section{Introduction}

$N$-methyl-D-aspartate (NMDA) receptors are ligand-gated ion channels that are involved in essential physiological processes in the central nervous system (CNS), such as neuronal development and synaptic plasticity (Traynelis et al., 2010), but they are also implicated in neuropsychiatric diseases, including schizophrenia and depression (Skolnick et al., 2009; Menniti et al., 2013; Zarate et al., 2013; Dutta et al., 2015; Goff, 2015).

This work was supported by H. Lundbeck A/S, Innovation Fund Denmark, University of Montana Research Grant Program, and the National Institutes of Health National Institute of General Medical Sciences [Grant P20GM103546] and National Institute of Neurological Disorders and Stroke [Grant R01NS097536].

${ }^{1}$ Current affiliation: Clinical Development, Chr. Hansen A/S, Hørsholm, Denmark.

https://doi.org/10.1124/mol.117.108944.

S This article has supplemental material available at molpharm. aspetjournals.org.
NMDA receptor subtypes. AICP is a full agonist at GluN1/2A (100\% response compared with glycine), a partial agonist at GluN1/2B and GluN1/2D (10\% and 27\%, respectively), and a highly efficacious superagonist at GluN1/2C receptors $(353 \%)$. Furthermore, AICP potencies are enhanced compared with $\mathrm{DCS}$ with $\mathrm{EC}_{50}$ values in the low nanomolar range (1.7 $\mathrm{nM}$ at GluN1/2C). We show that GluN1/2C superagonism of AICP and DCS is mediated by overlapping but distinct mechanisms and that AICP selectively enhances responses from recombinant GluN1/2C receptors in the presence of physiological glycine concentrations. This functional selectivity of AICP for GluN2C-containing NMDA receptors is more pronounced compared with DCS, suggesting that AICP can be a useful tool compound for uncovering the roles of GluN2C subunits in neuronal circuit function and in the development of new therapeutic strategies.

ABBREVIATIONS: 7-CKA, 7-chloro-4-oxo-1H-quinoline-2-carboxylic acid; ACPC, 1-aminocyclopropanecarboxylic acid; AICP, (R)-2-amino3-(4-(2-ethylphenyl)-1H-indole-2-carboxamido)propanoic acid; ATD, amino-terminal domain; CIQ, (3-chlorophenyl)-[6,7-dimethoxy-1[(4-methoxyphenoxy)methyl]-3,4-dihydro-1H-isoquinolin-2-yl]methanone; CNS, central nervous system; DCS, D-Cycloserine; D,L-AP5, 2-amino-5-phosphonopentanoic acid; HEK-293, human embryonic kidney 293; MK-801, dizocilpine; NMDA, N-methyl-D-aspartate; PYD, pyrrolidinone. 
2010). However, NMDA receptors mainly rely on synaptic release of glutamate for activation because extracellular glycine (or D-serine) is present at saturating or subsaturating concentrations (Bergeron et al., 1998; Billups and Attwell, 2003). Thus, the strength of phasic NMDA receptor activation by glutamate can be modulated by the tonic presence of agonists that bind the GluN1 glycine binding sites (Yang and Svensson, 2008; Lench et al., 2015). This idea has garnered considerable attention in the development of new therapeutic strategies and has led to numerous clinical trials with various NMDA receptor ligands that bind the GluN1 glycine binding site (Szakacs et al., 2012; Balu and Coyle, 2015; Goff, 2015; Schade and Paulus, 2016).

D-Cycloserine (DCS), a GluN1 glycine site agonist (McBain et al., 1989; Henderson et al., 1990; Watson et al., 1990; Priestley and Kemp, 1994), has been intensively studied due to its intriguing neuroactive properties (Monahan et al., 1989; Flood et al., 1992; Schuster and Schmidt, 1992; Walker et al., 2002). Administration of DCS can enhance extinction of fear in both rodents and humans, and this effect might be relevant in the treatment of some psychiatric disorders (Walker et al., 2002; Ressler et al., 2004; Davis et al., 2006; Gupta et al., 2013). The effects of DCS have been suggested to result from its unique in vitro pharmacological profile among recombinant NMDA receptor subtypes (GluN1/2A-D), in which the agonist efficacy of DCS is dependent on the glutamate-binding GluN2 subunits (Sheinin et al., 2001; Dravid et al., 2010). DCS is a partial agonist at GluN1/2A, GluN1/2B, and GluN1/2D receptors with lower maximal response compared with glycine and D-serine, whereas DCS has a higher maximal response at GluN1/2C receptors (Sheinin et al., 2001; Dravid et al., 2010). Thus, DCS is a GluN2C-selective NMDA receptor superagonist compared with the endogenous agonists glycine and D-serine.

The structural mechanism that mediates the GluN2 subtype-dependent agonist efficacy of DCS is unclear (Banke and Traynelis, 2003; Chen et al., 2008; Kussius and Popescu, 2009; Dravid et al., 2010). However, studies suggest that enhancement of both acquisition and extinction of conditioned fear responses by DCS administration is mediated by its actions as a GluN2C-selective superagonist and resulting potentiation of GluN2C-containing NMDA receptors in the amygdala (Hillman et al., 2011; Ogden et al., 2014).

Here, we describe the pharmacological profile of $(R)$-2-amino3-(4-(2-ethylphenyl)- $1 H$-indole-2-carboxamido)propanoic acid (AICP), which has been suggested to be a partial agonist at the NMDA receptor glycine site on the basis of a functional MK-801 (dizocilpine) binding assay in rat brain tissue (compound $R-26$ in Urwyler et al., 2009). The agonist activity of AICP is intriguing because the size of the chemical structure of AICP is dramatically increased compared with previously characterized GluN1 binding site agonists: glycine, DCS, D-serine, 1-aminocyclopropanecarboxylic acid (ACPC), and 1-aminocyclobutane-1-carboxylic acid (ACBC) (Chen et al., 2008) (Fig. 1A). We demonstrate that AICP is a highly potent and efficacious superagonist at GluN1/2C receptors with a more pronounced functional selectivity for GluN2C-containing NMDA receptors compared with DCS.

\section{Materials and Methods}

DNA Constructs and Ligands. Wild-type cDNA for human GluN1-1a (encoding GenBank: NP_015566.1) and human GluN2A, GluN2B, GluN2C, and GluN2D (encoding GenBank: NP_000824.1, NP_000825.2, NP_000826.2, and NP_000827.2, respectively) were synthesized in vitro (GenScript, Piscataway, NJ). Wild-type cDNA for rat GluN1-1a (GenBank: U08261), GluN2A (D13211), GluN2B (U11419), GluN2C (M91563), and GluN2D (L31611) were provided by S. Heinemann (Salk Institute), S. Nakanishi (Osaka Bioscience Institute), and P. Seeburg (University of Heidelberg). Mutant rat GluN1 and GluN2 constructs were generated using QuikChange protocols (Kvist et al., 2013). Amino acid composition for GluN2A(2C amino-terminal domain [ATD]) is 405-1464 from GluN2A and 1-414 from GluN2C, and amino acid composition for GluN2C-(2A amino-terminal domain [ATD]) is 1-402 from GluN2A and 413-1250 from GluN2C.

For expression in Xenopus oocytes, DNA constructs were linearized by restriction enzymes and used as templates for in vitro cRNA transcription. Amino acid residues are numbered based on the
A
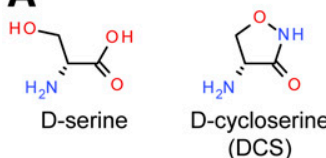
(DCS)<smiles>NC1(C(=O)O)CC1</smiles><smiles>NC1(C(=O)O)CCC1</smiles>

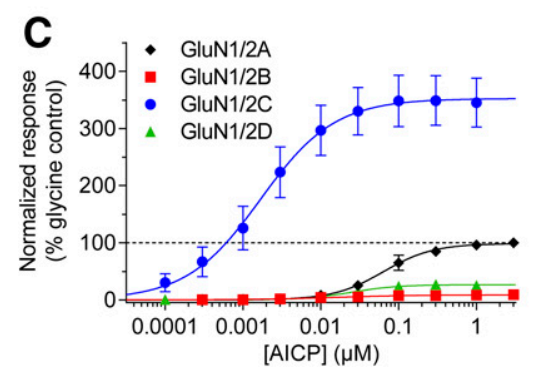

B
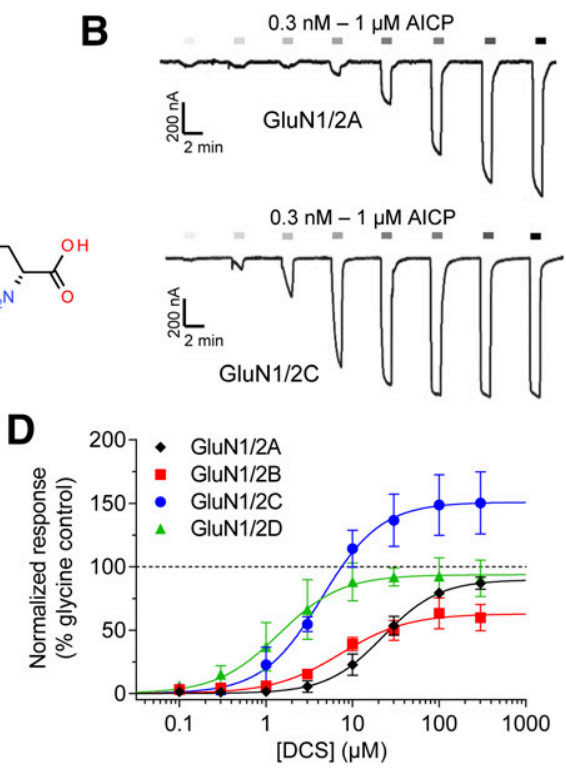

Fig. 1. Concentration-response data for AICP and DCS at human NMDA receptor subtypes. (A) Chemical structures of agonists at the GluN1 glycine binding site. (B) Representative recordings of concentration-response data for AICP in the presence of $100 \mu \mathrm{M}$ glutamate at recombinant human GluN1/2A and GluN1/2C receptors. (C, D) Concentrationresponse data for (C) AICP and (D) DCS at human NMDA receptor subtypes in the presence of $100 \mu \mathrm{M}$ glutamate. Data are mean \pm S.D. from 4 to 15 oocytes and are normalized to the maximal response to glycine $(100 \mu \mathrm{M})$ measured in the same recording. The $\mathrm{EC}_{50}$ values and relative agonist efficacy (i.e., maximal responses relative to glycine) are listed in Table 1. 
full-length polypeptide sequence, including the signal peptide (initiating methionine is 1 ). Glycine, DCS, and L-glutamate (hereafter glutamate) were obtained from Sigma-Aldrich (St. Louis, MO). AICP [(R)-2-amino-3-(4-(2-ethylphenyl)-1H-indole-2-carboxamido)propanoic acid] was synthesized as described elsewhere (Urwyler et al., 2009) at H. Lundbeck A/S (Valby, Denmark).

Two-Electrode Voltage-Clamp Recordings. Xenopus oocytes were purchased from Robert Weymouth (Xenopus 1, Dexter, MI) or Ecocyte Bioscience (Austin, TX, or Castrop-Rauxel, Germany). Oocytes were coinjected with cRNA encoding GluN1 and one of the four different GluN2 subunits, and were maintained at $18^{\circ} \mathrm{C}$ in modified Barth's solution containing (in $\mathrm{mM}$ ): $88 \mathrm{NaCl}, 1.0 \mathrm{KCl}$, 15 HEPES, $2.4 \mathrm{NaHCO}_{3}, 0.41 \mathrm{CaCl}_{2}, 0.82 \mathrm{MgSO}_{4}$, and $0.3 \mathrm{Ca}\left(\mathrm{NO}_{3}\right)_{2}$ (pH 7.5; osmolarity $0.22 \mathrm{Osm} / \mathrm{kg}$ ) supplemented with $0.1 \mathrm{U} / \mathrm{l}$ penicillin and $0.1 \mu \mathrm{g} / \mathrm{l}$ streptomycin.

Two-electrode voltage-clamp recordings were performed using Oocyte Clamp OC-725C amplifiers (Warner Instruments, Hamden, CT) and digitized by a Digidata 1320A 16-bit data acquisition system (Molecular Devices, Sunnyvale, CA). Oocytes were bathed with a flow rate of $5 \mathrm{ml} / \mathrm{min}$ using a gravity-driven perfusion system with extracellular recording solution containing (in $\mathrm{mM}$ ): $90 \mathrm{NaCl}, 1 \mathrm{KCl}$, 10 HEPES, $0.5 \mathrm{BaCl}_{2}$, and 0.01 EDTA ( $\mathrm{pH} 7.4$; osmolarity 0.20 $\mathrm{Osm} / \mathrm{kg}$ ). The voltage and current electrodes were made using a micropipette puller (Narishige, Amityville, NY) and were filled with $3 \mathrm{M} \mathrm{KCl}$ before use. In some cases, the micropipettes were also plugged with $1 \% \mathrm{w} / \mathrm{v}$ agar in $3 \mathrm{M} \mathrm{KCl}$ (type IX: Ultra-low Gelling Temperature; Sigma-Aldrich). Cells were clamped at a holding potential of $-40 \mathrm{mV}$ or $-60 \mathrm{mV}$, and recordings were performed 1 to 7 days after injection at room temperature $\left(20-25^{\circ} \mathrm{C}\right)$. AICP was dissolved at $10 \mathrm{mM}$ or $100 \mathrm{mM}$ in dimethylsulfoxide, and the concentration of dimethylsulfoxide was kept $\leq 1 \%$ in all experiments.

Whole-Cell Patch-Clamp Recordings. Human embryonic kidney 293 (HEK-293) cells were cultured in Dulbecco's modified Eagle medium with GlutaMax-I (Invitrogen) supplemented with $10 \%$ dialyzed fetal bovine serum, $1 \mathrm{mM}$ sodium pyruvate, $10 \mathrm{U} / \mathrm{ml}$ penicillin, and $10 \mu \mathrm{g} / \mathrm{ml}$ streptomycin, and plated on glass coverslips coated with $0.1 \mathrm{mg} / \mathrm{ml}$ poly-D-lysine in 24 -well plates approximately 48 hours before the experiments. Cells were transfected with plasmid cDNAs encoding GluN1 and GluN2 subunits at a ratio of 1:2 using the calcium phosphate precipitation method as previously described elsewhere (Hansen et al., 2013). The culture medium was replaced 4 to 5 hours after transfection with medium containing NMDA receptor antagonists 2-amino-5-phosphonopentanoic acid (D,L-AP5) and 7-chloro-4-oxo-1H-quinoline-2-carboxylic acid (7-CKA) $(200 \mu \mathrm{M}$ each) to minimize cytotoxicity, and experiments were performed approximately 24 hours after transfection.

Whole-cell voltage-clamp recordings were performed using an Axopatch 200B amplifier (Molecular Devices) at room temperature $\left(23^{\circ} \mathrm{C}\right)$ with the holding potential at $-60 \mathrm{mV}$. Electrodes were filled with internal solution containing (in mM) 110 D-gluconate, $110 \mathrm{CsOH}$, $30 \mathrm{CsCl}, 5 \mathrm{HEPES}, 4 \mathrm{NaCl}, 0.5 \mathrm{CaCl}_{2}, 2 \mathrm{MgCl}_{2}, 5$ BAPTA, $2 \mathrm{NaATP}$, and $0.3 \mathrm{NaGTP}(\mathrm{pH} 7.35$ with $\mathrm{CsOH}$ ), and the extracellular recording solution was composed of (in $\mathrm{mM}$ ) $150 \mathrm{NaCl}, 10 \mathrm{HEPES}, 3 \mathrm{KCl}, 0.5$ $\mathrm{CaCl}_{2}, 0.01$ EDTA, $20 \mathrm{mM}$ D-mannitol ( $\mathrm{pH} 7.4$ with $\mathrm{NaOH}$ ). Solution exchange was achieved using a two-barrel theta-glass pipette controlled by a piezoelectric translator, and the speed was measured to be $<1$ milliseconds (10\%-90\% rise times) from the open tip junctional potential.

Data Analysis. Data were analyzed using SigmaPlot 11.0 (Systat Software, San Jose, CA) or GraphPad Prism 6.05 (GraphPad Software, La Jolla, CA). Steady-state concentration-response curves were fitted to the Hill equation using variable slope, $I=I_{\max } /\left(1+10^{\wedge}\left(\left(\operatorname{logEC} \mathrm{C}_{50}-\right.\right.\right.$ $\left.\log [\mathrm{A}]) * \mathrm{n}_{\mathrm{H}}\right)$ ), where $I_{\max }$ is the maximum current in response to the agonist, $\mathrm{n}_{\mathrm{H}}$ is the Hill slope, $[\mathrm{A}]$ is the agonist concentration, and $\mathrm{EC}_{50}$ is the agonist concentration that elicits $50 \%$ of the maximum response. Raw data recordings were electronically filtered at $20 \mathrm{~Hz}$ (8-pole Bessel) and adjusted for baseline drift assuming a constant linear change throughout the recording. Current responses were measured

TABLE 1

Concentration-response data for glycine site agonists at NMDA receptor subtypes

Concentration-response data for glycine site agonists at recombinant human and rat NMDA receptor subtypes measured using two-electrode voltage-clamp electrophysiology in the presence of 100-300 $\mu \mathrm{M}$ glutamate.

\begin{tabular}{|c|c|c|c|c|c|c|c|}
\hline Receptor Subtype & Glycine Site Agonists & Receptor Species & $\mathrm{EC}_{50}(\mu \mathrm{M})$ & pEC $50 \pm$ S.E.M. & Rel. $I_{\max }(\%)$ & $\mathrm{n}_{\mathrm{H}}$ & $N$ \\
\hline \multicolumn{8}{|l|}{ GluN1/2A } \\
\hline & AICP & Human & 0.066 & $7.18 \pm 0.02$ & $100 \pm 2$ & 1.3 & 15 \\
\hline & & Rat & 0.036 & $7.49 \pm 0.05$ & $92 \pm 2$ & 1.3 & 29 \\
\hline & Glycine & Human & 1.2 & $5.91 \pm 0.01$ & $100 \pm 1$ & 1.7 & 6 \\
\hline & D-Serine & Human & 1.8 & $5.75 \pm 0.02$ & $99 \pm 1$ & 1.8 & 5 \\
\hline & DCS & Human & 22.0 & $4.65 \pm 0.02$ & $90 \pm 2$ & 1.3 & 6 \\
\hline & & Rat & 18.0 & $4.75 \pm 0.01$ & $91 \pm 1$ & 1.6 & 13 \\
\hline \multicolumn{8}{|l|}{ GluN1/2B } \\
\hline & AICP & Human & 0.025 & $7.60 \pm 0.19$ & $10 \pm 1$ & 0.7 & 9 \\
\hline & & Rat & 0.014 & $7.86 \pm 0.03$ & $9 \pm 0$ & 1.1 & 14 \\
\hline & Glycine & Human & 0.58 & $6.24 \pm 0.02$ & $101 \pm 1$ & 2.2 & 6 \\
\hline & D-Serine & Human & 0.98 & $6.01 \pm 0.05$ & $97 \pm 2$ & 1.2 & 5 \\
\hline & DCS & Human & 7.3 & $5.14 \pm 0.06$ & $63 \pm 2$ & 1.1 & 4 \\
\hline & & Rat & 8.3 & $5.08 \pm 0.01$ & $61 \pm 0$ & 1.4 & 12 \\
\hline GluI $1 / 2 \mathrm{C}$ & AICP & Human & 0.0017 & $8.77 \pm 0.04$ & $353 \pm 6$ & 0.9 & 16 \\
\hline & & Rat & 0.0010 & $9.04 \pm 0.03$ & $339 \pm 10$ & 1.0 & 17 \\
\hline & Glycine & Human & 0.33 & $6.48 \pm 0.03$ & $103 \pm 1$ & 1.7 & 5 \\
\hline & D-Serine & Human & 0.47 & $6.33 \pm 0.03$ & $106 \pm 1$ & 1.6 & 5 \\
\hline & DCS & Human & 4.4 & $5.36 \pm 0.05$ & $151 \pm 5$ & 1.3 & 4 \\
\hline & & Rat & 2.8 & $5.55 \pm 0.01$ & $197 \pm 2$ & 1.5 & 18 \\
\hline \multicolumn{8}{|l|}{ GluN1/2D } \\
\hline & AICP & Human & 0.025 & $7.61 \pm 0.03$ & $27 \pm 1$ & 1.4 & 14 \\
\hline & Glycin & $\begin{array}{l}\text { Rat } \\
\text { Human }\end{array}$ & $\begin{array}{l}0.031 \\
0.14\end{array}$ & $\begin{array}{l}7.51 \pm 0.02 \\
6.84 \pm 0.04\end{array}$ & $\begin{array}{r}26 \pm 1 \\
100 \pm 2\end{array}$ & $\begin{array}{l}1.5 \\
1.6\end{array}$ & $\begin{array}{r}11 \\
5\end{array}$ \\
\hline & D-Serine & Human & 0.35 & $6.46 \pm 0.03$ & $101 \pm 1$ & 2.0 & 5 \\
\hline & DCS & Human & 3.1 & $5.51 \pm 0.06$ & $76 \pm 3$ & 1.5 & 6 \\
\hline & & Rat & 3.2 & $5.50 \pm 0.01$ & $97 \pm 0$ & 1.6 & 6 \\
\hline
\end{tabular}

$N$, number of oocytes; $\mathrm{n}_{\mathrm{H}}$, Hill coefficient; (Rel.) $I_{\max }$, fitted maximal response relative to the maximal response to glycine. 
as steady-state amplitudes. For graphical presentation, data points from each individual oocyte were normalized to the maximum current response to glutamate and glycine (saturating concentrations) in the same recording. Whole-cell patch-clamp recordings were analyzed using AxoGraph (www.axograph.com).

\section{Results}

Agonist Efficacy of AICP Is Highly NMDA Receptor Subtype-Dependent. We evaluated the activity of AICP using two-electrode voltage-clamp electrophysiology for recombinant NMDA receptor subtypes expressed in Xenopus oocytes (human GluN1/2A, GluN1/2B, GluN1/2C, and GluN1/2D receptors). Because this ligand was previously described as a GluN1 glycine site agonist (Urwyler et al., 2009), we determined the AICP concentration-response relationship in the continuous presence of $100 \mu \mathrm{M}$ glutamate (i.e., saturating concentration of glutamate). AICP was a highly potent agonist with nanomolar $\mathrm{EC}_{50}$ values at all four human NMDA receptor subtypes, but displayed a remarkable variation in agonist efficacy among the subtypes (Fig. 1; Table 1). At human GluN1/2A receptors, AICP showed characteristics as a full agonist with a maximal response at $100 \%$ compared with glycine (i.e., relative agonist efficacy), whereas AICP was a partial agonist with relative agonist efficacies of $10 \%$ and $27 \%$ at human GluN1/2B and GluN1/2D receptors, respectively (Fig. 1C; Table 1). Surprisingly, AICP displayed a high relative agonist efficacy of $353 \%$ at human GluN1/2C receptors (Fig. 1C; Table 1). Similar results were observed for activation of rat NMDA receptor subtypes by AICP (Table 1).

To directly compare the agonist activity of AICP with those of the endogenous agonists glycine and D-serine as well as the exogenous agonist DCS, we evaluated these other glycine site agonists at human NMDA receptor subtypes using the same experimental conditions (Table 1). DCS was a partial agonist at human GluN1/2A, GluN1/2B, and GluN1/2D receptors with relative agonist efficacies of $90 \%, 63 \%$, and $76 \%$, respectively, but displayed increased relative agonist efficacy of $151 \%$ at human GluN1/2C receptors (Fig. 1D and Table 1). This pharmacological profile of DCS at human NMDA receptor subtypes is similar to the previously reported profiles at rat NMDA receptor subtypes (Sheinin et al., 2001; Dravid et al., 2010) (Table 1).

The potency of AICP was remarkably high with $\mathrm{EC}_{50}$ values of $1.7 \mathrm{nM}$ to $66 \mathrm{nM}$ at human GluN1/2A-D receptors (Table 1). For comparison, the $\mathrm{EC}_{50}$ values of DCS was $3.1 \mu \mathrm{M}$ to $22 \mu \mathrm{M}$ at human GluN1/2A-D receptors, respectively, which are 120to 2,600-fold higher (i.e., lower potencies) than the corresponding $\mathrm{EC}_{50}$ values of AICP (Table 1). Thus, AICP displays a preference for GluN1/2C receptors with more than an order of magnitude higher potency compared with the other NMDA receptor subtypes and is thereby more selective than DCS.

In summary, we identify AICP as a highly potent and efficacious superagonist at GluN1/2C receptors. The high potency and GluN2 subunit dependency of AICP is unprecedented among NMDA receptor glycine site agonists described to date (Chen et al., 2008).

AICP Selectively Binds the GluN1 Glycine Site but Not the GluN2 Glutamate Site. To discern whether some activity of AICP is mediated by binding to the glutamate binding site, we evaluated whether AICP can replace glutamate as GluN2 agonist. Applications of glycine alone or AICP alone were unable to produce current responses in Xenopus oocytes expressing GluN1/2A and GluN1/2C receptors (Fig. 2A). Furthermore, coapplication of AICP plus glycine did not produce observable current responses compared with activation by glutamate plus glycine (Fig. 2A). Thus, AICP does not have any agonist activity at the glutamate site of these NMDA receptor subtypes.

To evaluate whether AICP could act as competitive antagonist at the glutamate site, full concentration-response curves were generated in the presence of increasing concentrations of

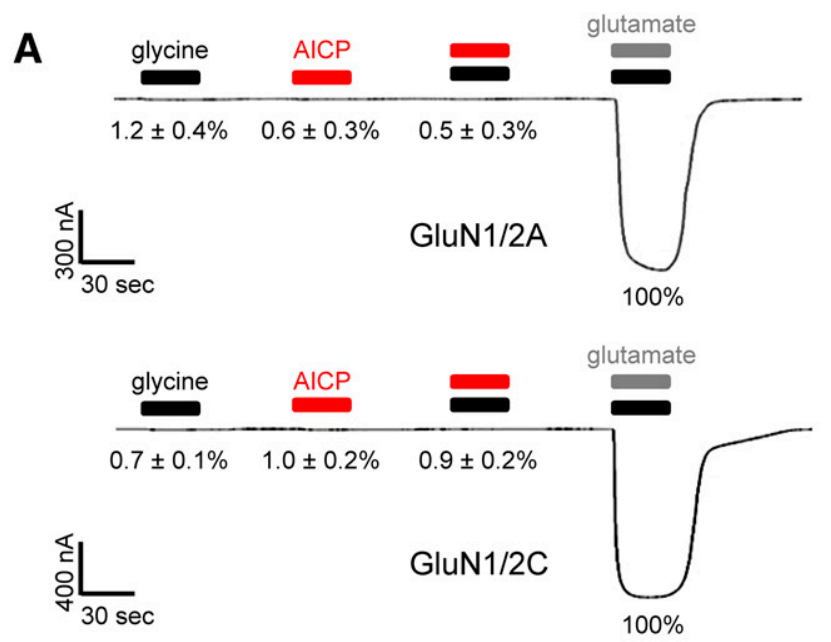

B
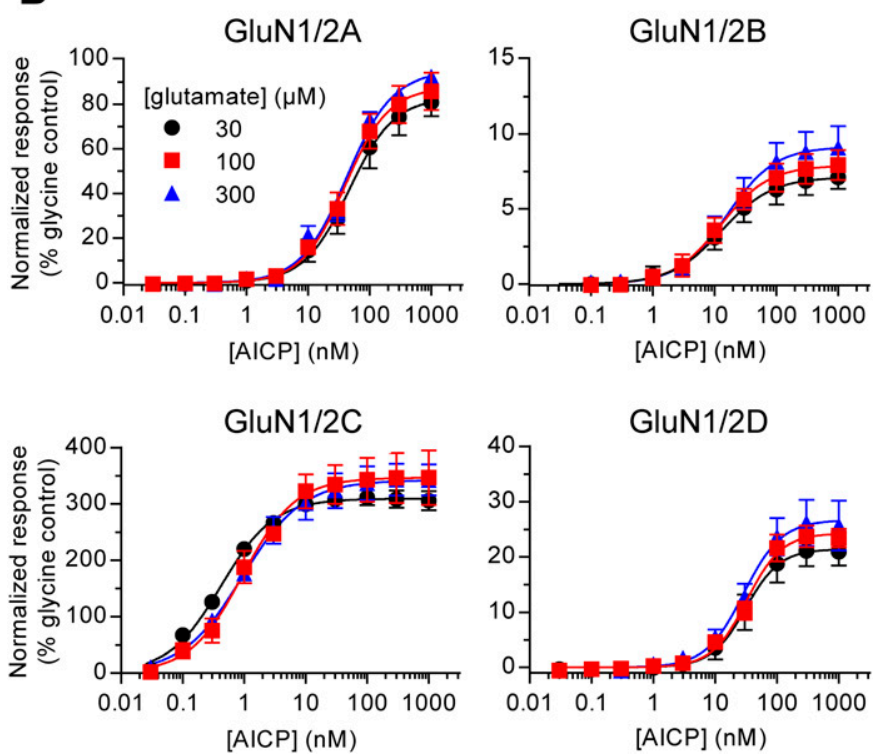

Fig. 2. Relationship between the glutamate binding site and AICP activity. (A) Representative two-electrode voltage-clamp recordings of responses at rat GluN1/2A and GluN1/2C receptors to $100 \mu \mathrm{M}$ glycine alone, $10 \mu \mathrm{M}$ AICP alone, $100 \mu \mathrm{M}$ glycine plus $10 \mu \mathrm{M}$ AICP, or $100 \mu \mathrm{M}$ glutamate plus $100 \mu \mathrm{M}$ glycine. The mean responses normalized to control (glutamate plus glycine) \pm S.E.M. from 6 to 8 oocytes are listed below the respective ligand applications. (B) Concentration-response data for AICP at rat NMDA receptor subtypes in the presence of either 30,100 , or $300 \mu \mathrm{M}$ glutamate. Data are mean \pm S.D. from 3 to 16 oocytes and are normalized to the maximal response to glycine $(100 \mu \mathrm{M})$ plus the corresponding concentration of glutamate $(30,100$, or $300 \mu \mathrm{M})$ measured in the same recording. The $\mathrm{EC}_{50}$ values and relative agonist efficacies (i.e., maximal responses relative to glycine) are listed in Supplemental Table 1. 

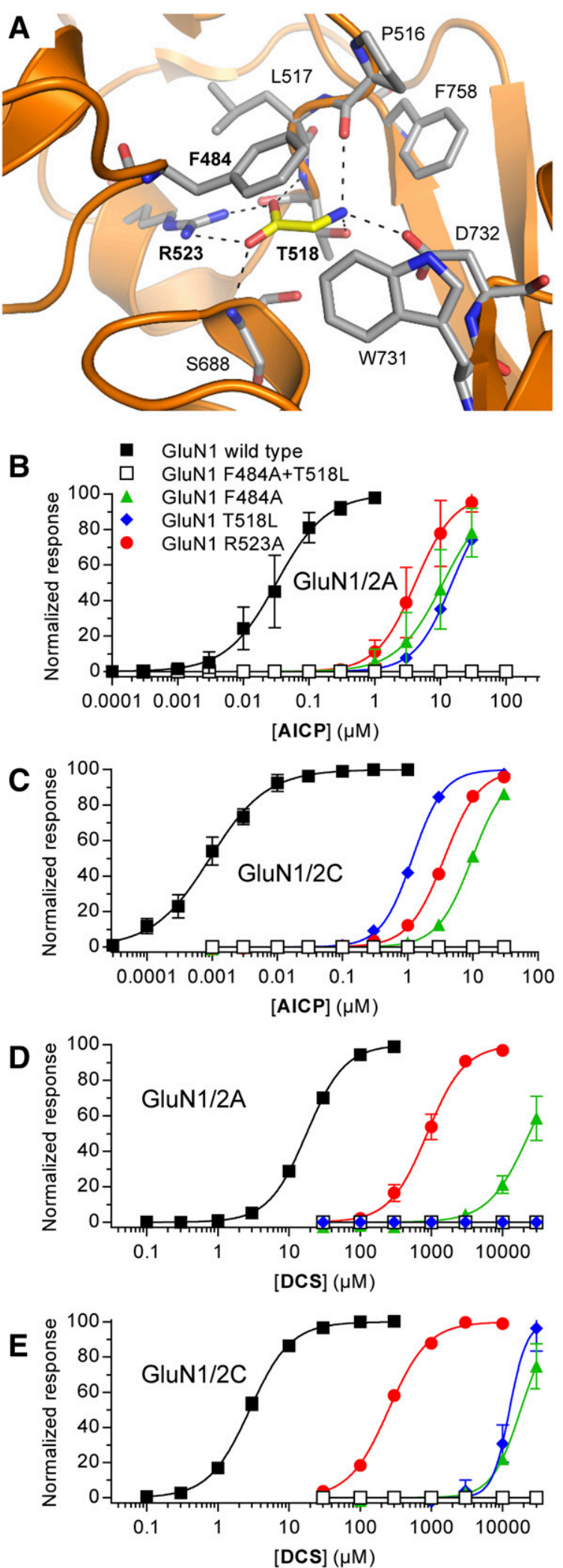

Fig. 3. Activity of AICP and DCS at NMDA receptors with mutations in the glycine binding site. (A) Structure of glycine bound in the agonist binding site of the GluN1 subunit (PDB ID 5I57; Yi et al., 2016). Dashed lines indicate polar interactions between glycine (yellow carbon) and GluN1 residues (gray carbon). Mutated residues are indicated in bold text. (B-E) Concentration-response data for AICP (B and C) and DCS (D and $\mathrm{E}$ ) at rat GluN1/2A and GluN1/2C receptors with mutations in the glycine binding site measured using two-electrode voltage-clamp glutamate at GluN1/2A-D receptors (Fig. 2B; Supplemental Table 1). Changing the glutamate concentration up to 10 -fold from $30 \mu \mathrm{M}$ to $300 \mu \mathrm{M}$ did not result in consistent significant effects on the potency or relative agonist efficacy of AICP, demonstrating that the partial agonism of AICP at GluN1/2B and GluN1/2D receptors is not mediated by inhibition of glutamate binding (see Supplemental Table 1 for statistical tests).

Although AICP is an $\alpha$-amino acid, the chemical structure is very different in terms of size and stereoelectronic properties compared with other GluN1 agonists (Fig. 1A). The different structure of AICP may enable binding to other sites on the NMDA receptor and/or produce activation independent of the orthosteric GluN1 agonist binding site. To evaluate this possibility, we generated AICP concentration-response data at GluN1/2A and GluN1/2C receptors harboring mutations in the GluN1 glycine binding site (Fig. 3A). These GluN1 mutants (F484A, T518L, and R523A) are known to dramatically increase glycine $\mathrm{EC}_{50}$ (i.e., reduce potency) and the combination of two of these mutations in GluN1 (F484A + T518L) completely abolish NMDA receptor activation (Kvist et al., 2013). Similar to glycine (Kvist et al., 2013), the potency of AICP was dramatically reduced (140- to 10,000-fold) at mutant GluN1/2A and GluN1/2C receptors compared with the respective wild-type receptors (Fig. 3, B and C; Supplemental Table 2). Furthermore, measurable current responses to AICP were not observed for receptors containing the GluN1 F484A+ T518L double-mutant, which is also insensitive to glycine binding (Fig. 3, B and C; Supplemental Table 2). Similar results were observed for DCS at the mutant GluN1/2A and GluN1/2C receptors (Fig. 3, D and E; Supplemental Table 2). Like glycine and DCS, activation of NMDA receptors by AICP thus depends on residues in the orthosteric binding pocket of GluN1.

Extracellular recording solutions are typically contaminated by glycine in low nanomolar concentrations (e.g., approximately $20 \mathrm{nM}$; Johnson and Ascher, 1992). AICP could therefore display apparent agonist activity in the nominal absence of glycine if this ligand is a positive allosteric modulator of glycine binding. To evaluate this possibility, we compared AICP concentration-response data at NMDA receptor subtypes in the continuous presence of saturating glutamate plus either low glycine $(0.6 \mu \mathrm{M})$ or high glycine (100 $\mu \mathrm{M})$.

At low AICP levels, the concentration-response data are comparable to activation by glycine alone at the respective NMDA receptor subtypes (Fig. 4; Supplemental Table 3). That is, the AICP concentration-response data in the presence of $0.6 \mu \mathrm{M}$ glycine begin at different levels depending on the NMDA receptor subtype, because glycine potency differs among GluN2 subunits (Chen et al., 2008). However, the concentration-response data at the NMDA receptor subtypes plateau at similar levels in high concentrations of AICP (Fig. 4; Supplemental Table 3). AICP showed properties as a functional antagonist at GluN1/2B and GluN1/2D receptors, consistent with AICP being a partial agonist at these NMDA receptor subtypes. Most notably, the potencies

recordings. The responses are normalized to the fitted maximal response. Data are mean \pm S.D. from 3 to 29 oocytes, and the $\mathrm{EC}_{50}$ values are listed in Supplemental Table 2. 
A

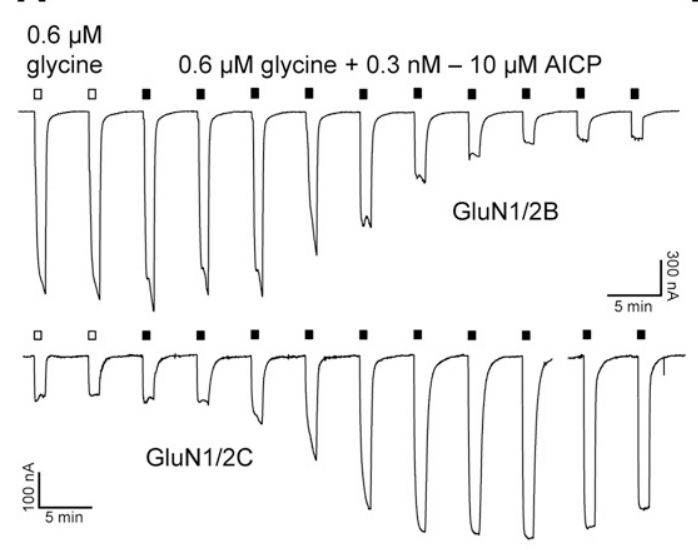

B
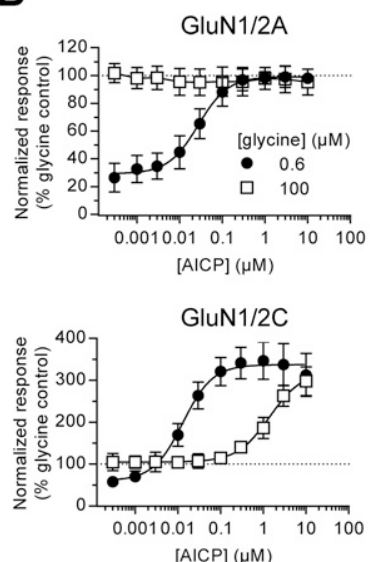
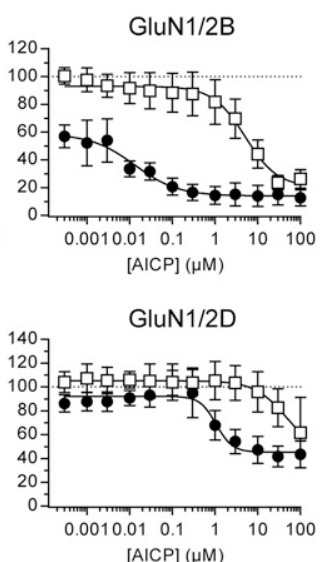

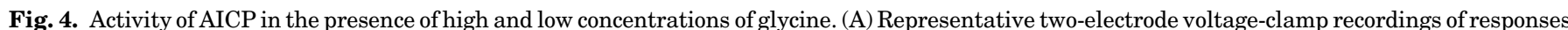

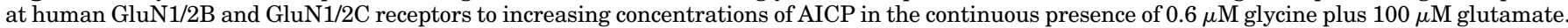

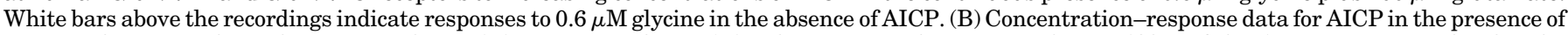

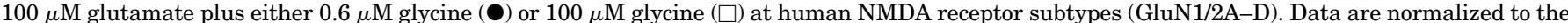

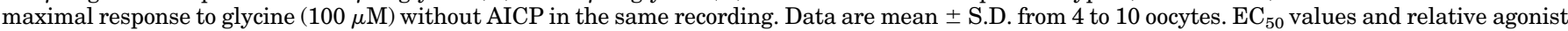
efficacies (i.e., maximal responses relative to glycine) are listed in Supplemental Table 3.

by which AICP either increase glycine-activated currents at GluN1/2C or inhibit these currents at GluN1/2B and GluN1/2D receptors were significantly reduced in the presence of $100 \mu \mathrm{M}$ glycine compared with $0.6 \mu \mathrm{M}$ glycine (Fig. 4; see Supplemental Table 3 for statistical tests). These results demonstrate that AICP and glycine compete for binding to the GluN1 subunit and that AICP is not a positive allosteric modulator of glycine binding (e.g., see Kenakin and Black, 1978).

In summary, the combination of results presented in Figs. 2-4 establish that neither partial agonism nor superagonism of AICP is mediated by additional activity through binding to a modulatory site or the glutamate site in GluN2 subunits. Rather, AICP selectively binds the GluN1 glycine site with agonist activities that are highly dependent on the identity of the GluN2 subunit.

Agonist Efficacy of AICP Is Influenced by Multiple Structural Domains in the GluN2 Subunit. Molecular dynamics simulations have suggested that interactions between the agonist binding domains of GluN1 and GluN2 subunits contribute to the differential agonist efficacy of DCS at GluN1/2B and GluN1/2C receptors (Dravid et al., 2010). This previous study also demonstrated that the nonconserved residue GluN2C Gln800 (Glu790 in GluN2B; Fig. 5A) in the agonist binding domain dimer interface mediated a portion of the GluN2-dependent activity of DCS (Dravid et al., 2010). We evaluated AICP and DCS on rat GluN1/2B-E790Q and GluN1/2C-Q800E receptors and compared agonist efficacies and potencies with wild-type receptors (Fig. 5, B and C; Supplemental Table 4).

The relative DCS agonist efficacy was increased from $61 \%$ at wild-type GluN1/2B to $81 \%$ at GluN1/2B-E790Q, whereas DCS agonist efficacy was reduced from $197 \%$ at wild-type GluN1/2C to $143 \%$ at GluN1/2C-Q800E receptors (Fig. 5C; Supplemental Table 4), consistent with the previous report by Dravid et al. (2010). However, the relative AICP agonist efficacy was unchanged at GluN1/2B-E790Q compared with wild-type GluN1/2B, but AICP agonist efficacy was increased from $339 \%$ at wild-type GluN1/2C to
$607 \%$ at GluN1/2C-Q800E receptors (Fig. 5B; Supplemental Table 4). The potency of AICP was reduced 12 -fold (i.e., $\mathrm{EC}_{50}$ increased) by the GluN2C Q800E mutation compared with wild type, whereas DCS potencies were unaffected by the mutations (Fig. 5, B and C; Supplemental Table 4). Thus, the potency and efficacy of AICP are influenced by GluN2C Gln800 in the agonist binding domain dimer interface, which is also influencing the GluN2-dependent agonist efficacy of DCS.

The amino-terminal domain (ATD) (Fig. 5A) of GluN2 subunits has been identified as a modulatory domain that regulates open probability (i.e., agonist efficacy) and mediates many of the differences in functional and pharmacological properties between GluN1/2A-D NMDA receptor subtypes (Gielen et al., 2009; Yuan et al., 2009; Hansen et al., 2013). We evaluated the effect of swapping the ATD between GluN2A and GluN2C subunits on the agonist activities of AICP and DCS.

For GluN1/2A-(2C ATD) receptors with the ATD from GluN2C, the relative agonist efficacy of DCS was slightly decreased to $75 \%$ compared with $91 \%$ at wild-type GluN1/2A, whereas the relative agonist efficacy of AICP was unchanged (Fig. 5D; Supplemental Table 4). By contrast, the superagonist activity of both AICP and DCS was completely removed at GluN1/2C-(2A ATD) receptors with the ATD from GluN2A (Fig. 5D; Supplemental Table 4). In addition, swapping the ATD between GluN2A and GluN2C subunits did not change the $\mathrm{EC}_{50}$ values of AICP and DCS (Fig. 5D; Supplemental Table 4). These results demonstrate that the GluN2C ATD is required for the superagonist activity of both AICP and DCS.

In summary, the GluN2-dependent differences in relative agonist efficacies of AICP and DCS are influenced by the GluN2 ATD as well as residues located in the agonist binding domain dimer interface, suggesting that multiple and possibly complementary mechanisms govern the agonist efficacy of GluN1 ligands (Dravid et al., 2010). However, the opposing effects of the GluN2C Q800E mutation on the relative agonist efficacies of AICP and DCS, suggest that superagonism for these two ligands at GluN1/2C is mediated by overlapping, but distinct mechanisms. 
A

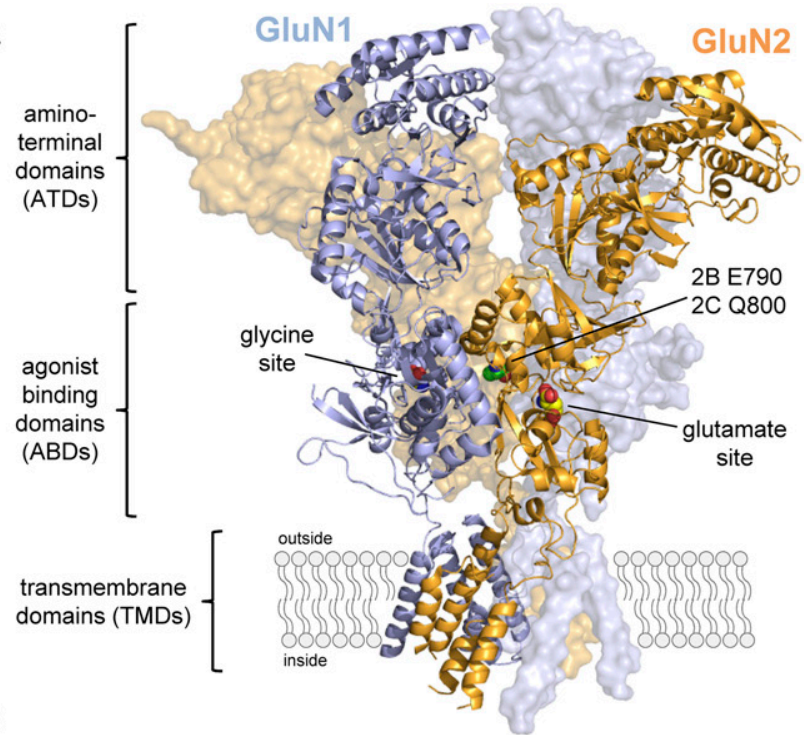

B

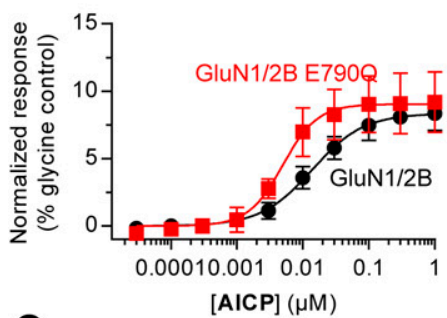

C
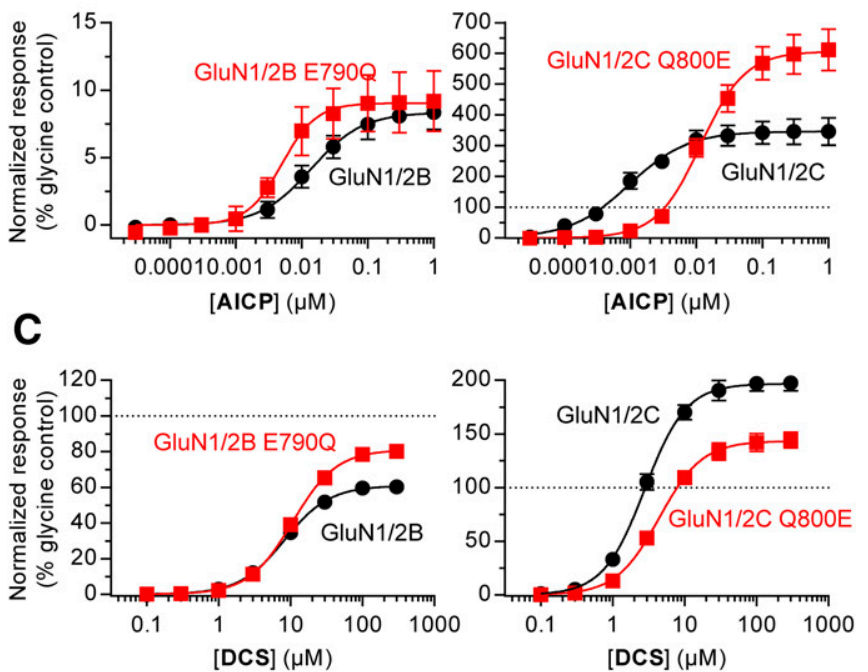

D
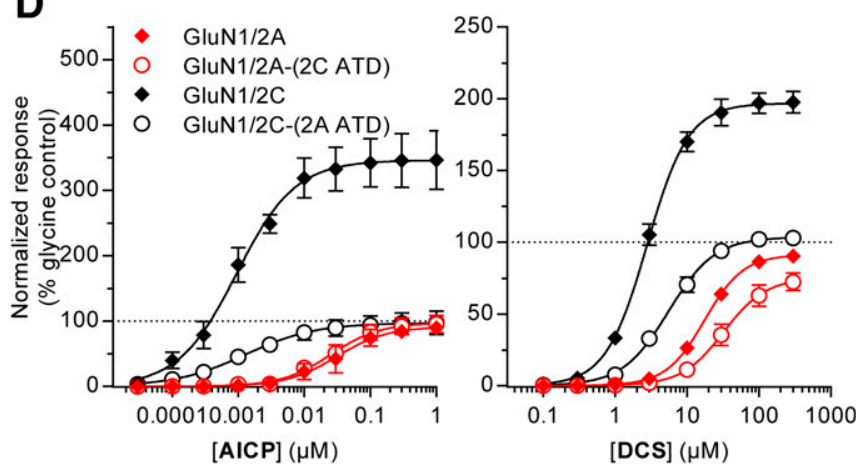

Fig. 5. Relative agonist efficacy of AICP is controlled by residues in multiple receptor domains. (A) NMDA receptor structure (PDB ID 4PE5; Karakas and Furukawa, 2014) illustrating the subunit arrangement and the layered domain organization composed of the transmembrane domains (TMDs) and two extracellular layers formed by the agonist binding domains (ABDs) and the ATDs. Agonist binding sites for glycine in GluN1 and glutamate in GluN2 subunits as well as the known positions of homologous residues E790 in GluN2B and Q800 in GluN2C are highlighted. (B, C) Concentration-response data for (B) AICP and (C) DCS measured using two-electrode voltage-clamp recordings at rat wildtype and mutant GluN1/2B and GluN1/2C receptors. Data are mean \pm S.D. from 8 to 18 oocytes. (D) Concentration-response data for AICP and DCS measured using two-electrode voltage-clamp recordings at rat GluN1/2A and GluN1/2C receptors and receptors with interchanged
Agonist Efficacy of AICP Is Not Mediated by Changes in Receptor Desensitization. Two-electrode voltageclamp recordings provide steady-state measurements (i.e., current responses are at equilibrium) using a perfusion system that is relatively slow due to the large size of Xenopus oocytes. Differences among NMDA receptor subtypes related to fast components of the agonist response time course (e.g., desensitization) thus cannot be discerned in these experiments.

The apparent partial agonist activity of AICP observed using two-electrode voltage-clamp electrophysiology could be related to increased desensitization of AICP compared with glycine responses. Similarly, the apparent superagonist activity of AICP may be mediated by reduced desensitization of AICP compared with glycine responses. To evaluate these possibilities, we performed fast-application whole-cell patchclamp recordings of rat GluN1/2B and GluN1/2C receptors expressed in HEK-293 cells.

The time course of NMDA receptor responses were measured after rapid application and removal of supersaturating glycine $(100 \mu \mathrm{M})$ or $\operatorname{AICP}(10 \mu \mathrm{M})$ in the continuous presence of saturating glutamate $(100 \mu \mathrm{M})$ (Fig. 6). These measurements revealed two marked differences between AICP and glycine responses, which are observed for both NMDA receptor subtypes. First, the rise time (10\%-90\%) of AICP responses was slower than that of glycine responses (Fig. 6C; Table 2). Second, the deactivation time course of AICP responses was remarkably slow compared with that of glycine (Fig. 6D; Table 2), consistent with the unprecedented high potency of AICP at both GluN1/2B and GluN1/2C receptors compared with glycine (Table 1).

Importantly, desensitization was slightly increased for AICP responses compared with glycine responses (Fig. 6E; Table 2), but the small differences are not able to account for the partial agonist activity of AICP observed using twoelectrode voltage-clamp electrophysiology. Furthermore, amplitudes of AICP responses relative to glycine responses (i.e., relative agonist efficacy) were consistent with two-electrode voltage-clamp measurements at GluN1/2B and GluN1/2C receptors (Fig. 6, E and F; Table 2). These results demonstrate that partial agonism of AICP at GluN1/2B and superagonism at GluN1/2C are not mediated by changes in desensitization properties.

AICP Selectively Enhances Activation of GluN1/2C Receptors in the Presence of Glycine. The high potency and increased relative agonist efficacy of AICP raises the possibility that AICP can produce a more pronounced enhancement of current responses from GluN2C-containing NMDA receptors compared with DCS in the presence of physiological concentrations of glycine $(\sim 1-10 \mu \mathrm{M}$; Bergeron et al., 1998; Billups and Attwell, 2003). To explore this idea, we compared the concentration-response relationship for AICP and DCS in the continuous presence of $10 \mu \mathrm{M}$ glycine and $300 \mu \mathrm{M}$ glutamate at recombinant rat NMDA receptor subtypes.

ATDs [GluN1/2A-(2C ATD) and GluN1/2C-(2A ATD)]. Data are mean \pm S.D. from 6 to 29 oocytes. The $\mathrm{EC}_{50}$ values and relative agonist efficacies (i.e., maximal responses relative to glycine) are listed in Supplemental Table 4 

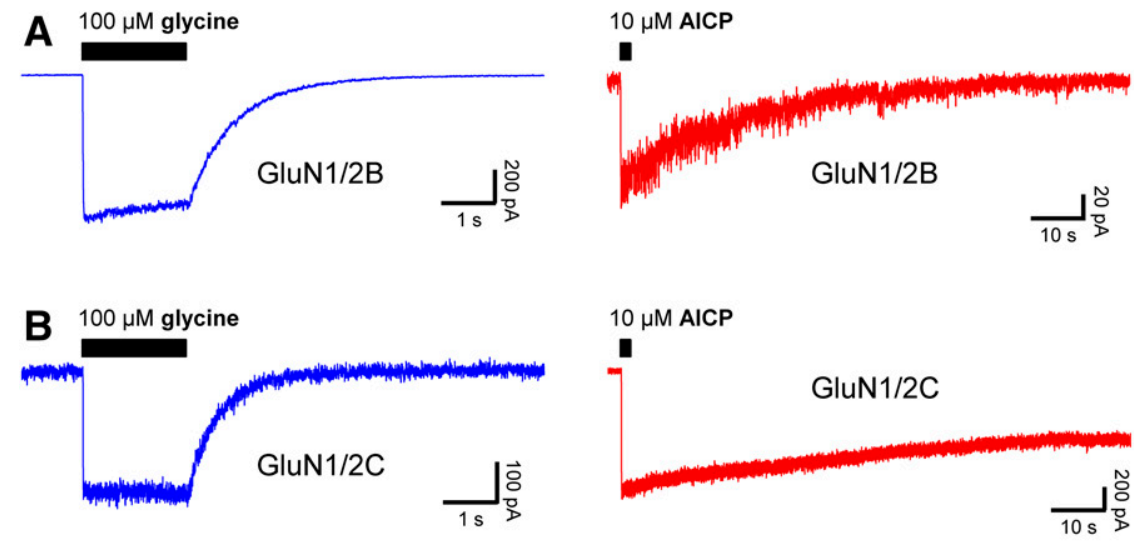

Fig. 6. Desensitization properties of NMDA receptors are not different for glycine and AICP responses. (A, B) Representative fast-application whole-cell patchclamp of responses at rat GluN1/2B and GluN1/2C receptors to long exposures ( 2 seconds) with $100 \mu \mathrm{M}$ glycine or $10 \mu \mathrm{M}$ AICP in the continuous presence of $100 \mu \mathrm{M}$ glutamate. The glycine (blue) and AICP (red) responses are shown on different time scales. (C)

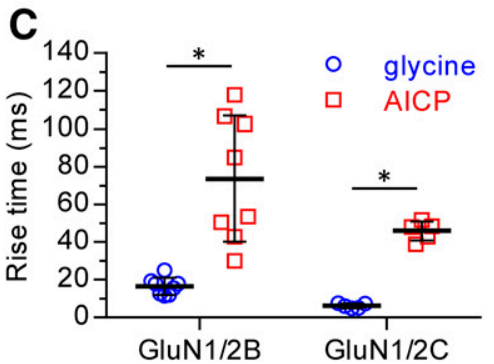

D

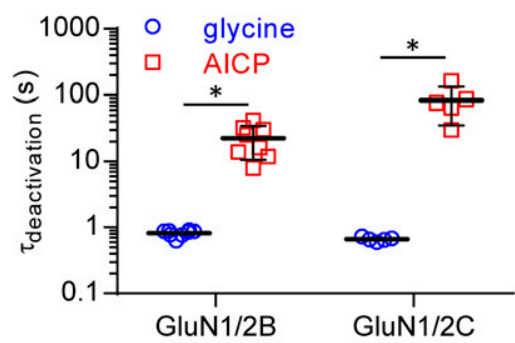

$\mathbf{F}$

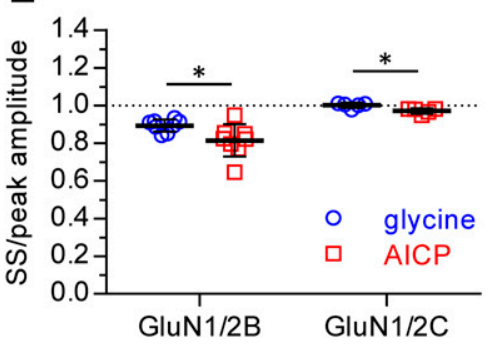

Scatterplot of rise times $(10 \%-90 \%)$ of glycine and AICP responses from individual cells (D) Scatterplot of deactivation time constants $\left(\tau_{\text {deactivation }}\right)$ of glycine and AICP responses from individual cells. (E) Scatterplot of the ratio between steady-state (SS) and peak amplitudes of glycine and AICP responses from individual cells. (F) Scatterplot of steady-state (SS) and peak amplitudes of AICP responses relative to the glycine response in the same cell. Mean \pm S.D. is indicated in the scatterplots. $N=8$ and $N=5$ cells for GluN1/2B and GluN1/2C, respectively. *Statistically significantly different from the response to glycine at the same receptor subtype $(P<0.05$, unpaired twotailed $t$ test). Values are listed in Table 2.
Under these experimental conditions, AICP at submicromolar concentrations robustly enhanced GluN1/2C receptor function with an $\mathrm{EC}_{50}$ of $0.56 \mu \mathrm{M}\left(\mathrm{pEC}_{50}=6.25 \pm 0.02\right)$ and a maximal response of $323 \% \pm 18 \%$ compared with glycine $(10 \mu \mathrm{M})$, whereas DCS required higher concentrations to produce smaller increases in GluN1/2C receptor current responses with an $\mathrm{EC}_{50}$ of $94 \mu \mathrm{M}\left(\mathrm{pEC}_{50}=4.03 \pm 0.01\right)$ and $\mathrm{a}$ maximal response of $174 \% \pm 2 \%$ (Fig. 7, A-D). In addition, $\mathrm{AICP}$ was a functional antagonist of GluN1/2B receptors with an $\mathrm{IC}_{50}$ of $0.81 \mu \mathrm{M}\left(\mathrm{pIC}_{50}=6.11 \pm 0.05\right)$ and a maximal response of $6 \% \pm 2 \%$ compared with glycine $(10 \mu \mathrm{M})$, consistent with its potent partial agonist activity at this NMDA receptor subtype (Fig. 7, A-D). Similar robust enhanced activation of GluN1/2C and reduced activation of GluN1/2B receptors were observed in response to $1 \mu \mathrm{M}$ AICP in the continuous presence of either $1 \mu \mathrm{M}$ or $10 \mu \mathrm{M}$ glycine (Fig. 7, E and F).

These results demonstrate that AICP selectively enhances current responses mediated by GluN2C-containing NMDA

TABLE 2

Time course of macroscopic NMDA receptor responses to glycine and AICP

Data are from whole-cell patch-clamp recordings of rat GluN1/2B and GluN1/2C receptors expressed in HEK-293 cells. Here, $100 \mu \mathrm{M}$ glycine or $10 \mu \mathrm{M}$ AICP were applied using rapid solution exchange in the continuous presence of $100 \mu \mathrm{M}$ glutamate (see Materials and Methods). Steady-state (SS) and peak responses were normalized to the glycine response from the same cell. The deactivation time course was described using mono-exponential fits, and the time constant is listed $\left(\tau_{\text {deactivation }}\right) . N$ is the number of cells, and the values are mean \pm S.E.M.

\begin{tabular}{|c|c|c|c|c|}
\hline \multirow{2}{*}{ Response } & \multicolumn{2}{|c|}{ GluN1/2B } & \multicolumn{2}{|c|}{ GluN1/2C } \\
\hline & Glycine & AICP & Glycine & AICP \\
\hline Rise time $(10 \%-90 \%, \mathrm{~ms})$ & $16 \pm 2$ & $74 \pm 12$ & $6.2 \pm 0.6$ & $46 \pm 2$ \\
\hline SS/peak amplitude & $89 \pm 1$ & $81 \pm 3$ & $100 \pm 1$ & $97 \pm 1$ \\
\hline Peak amplitude (\% of glycine) & 100 & $8.1 \pm 1.1$ & 100 & $388 \pm 18$ \\
\hline SS amplitude ( $\%$ of glycine) & 100 & $7.4 \pm 1.0$ & 100 & $376 \pm 18$ \\
\hline $\begin{array}{l}\tau_{\text {deactivatiom }}(\mathrm{s}) \\
N\end{array}$ & $\begin{array}{c}0.820 \pm 0.033 \\
8\end{array}$ & $22.6 \pm \frac{4}{8} 4.2$ & $\begin{array}{c}0.662 \pm 0.021 \\
5\end{array}$ & $84.3 \pm 22.0$ \\
\hline
\end{tabular}


A
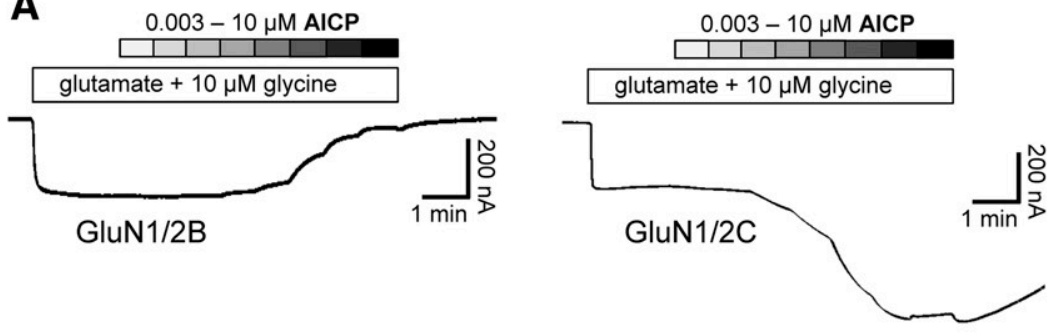

C
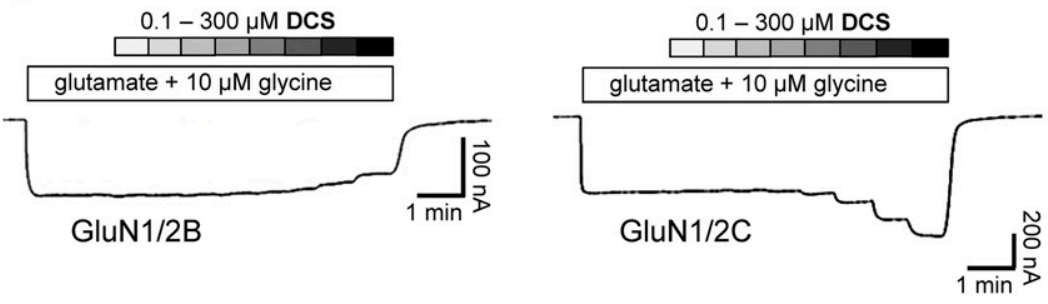

B

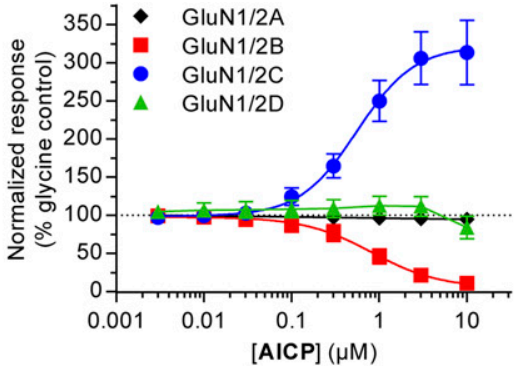

D

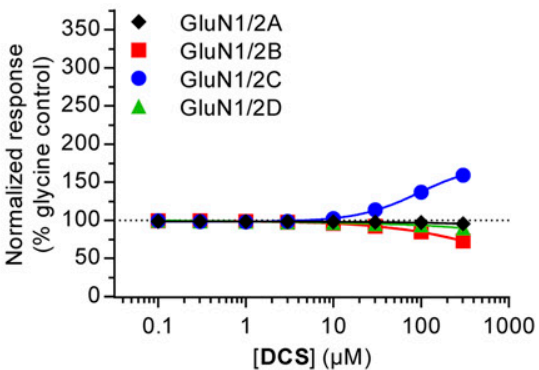

E

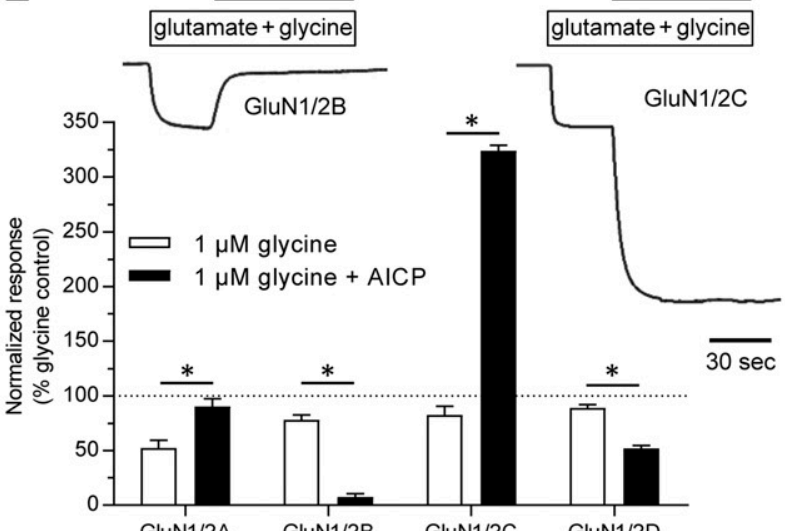

$\mathbf{F}$
AICP glutamate + glycine

AICP

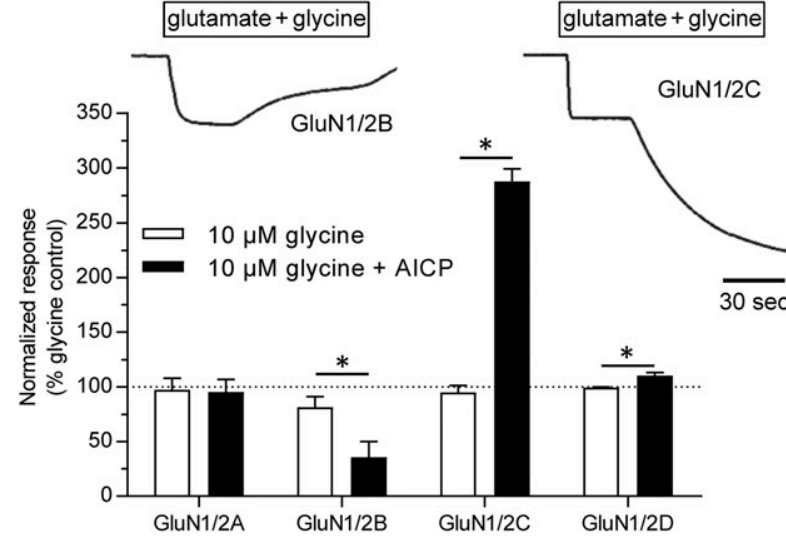

Fig. 7. AICP enhances responses from GluN1/2C receptors in the presence of physiologically relevant concentrations of glycine. (A) Representative twoelectrode voltage-clamp recordings of responses at rat GluN1/2B and GluN1/2C receptors to increasing concentrations of AICP in the continuous presence of $10 \mu \mathrm{M}$ glycine plus $300 \mu \mathrm{M}$ glutamate. (B) Concentration-response data for AICP in the presence of $10 \mu \mathrm{M}$ glycine plus $300 \mu \mathrm{M}$ glutamate at rat GluN1/2A-D. Data are mean \pm S.D. from six oocytes for each subtype. (C) Representative two-electrode voltage-clamp recordings of responses at rat GluN1/2B and GluN1/2C receptors to increasing concentrations of DCS in the continuous presence of $10 \mu \mathrm{M}$ glycine plus $300 \mu \mathrm{M}$ glutamate. (D) Concentration-response data for DCS in the presence of $10 \mu \mathrm{M}$ glycine plus $300 \mu \mathrm{M}$ glutamate at rat GluN1/2A-D. Data are mean \pm S.D. from six to seven oocytes. (E, F) Representative two-electrode voltage-clamp recordings of responses at rat GluN1/2B and GluN1/2C receptors to (E) $1 \mu \mathrm{M}$ glycine or (F) $10 \mu \mathrm{M}$ glycine plus $300 \mu \mathrm{M}$ glutamate with and without $1 \mu \mathrm{M}$ AICP. Bar graphs of responses from rat GluN1/2A-D receptors to $1 \mu \mathrm{M}$ AICP in the presence of either (E) $1 \mu \mathrm{M}$ glycine or (F) $10 \mu \mathrm{M}$ glycine plus $300 \mu \mathrm{M}$ glutamate normalized to the response to $100 \mu \mathrm{M}$ glycine plus $300 \mu \mathrm{M}$ glutamate in the same recording. The responses are measured using two-electrode voltage-clamp electrophysiology and data are mean \pm S.D. from 4 oocytes for each condition. *Statistically significantly different from the response in the absence of AICP at the same receptor subtype $(P<0.05$, paired two-tailed $t$ test).

receptors in the presence of physiologically relevant concentrations of glycine with markedly higher potency and efficacy compared with DCS.

\section{Discussion}

In this study, we demonstrate unique GluN2-dependent differences in agonist efficacy of the glycine site agonist AICP at recombinant NMDA receptor subtypes (GluN1/2A-D). AICP is a full agonist at GluN1/2A (100\% response compared with glycine), a partial agonist at GluN1/2B and GluN1/2D ( $10 \%$ and $27 \%$, respectively), and a highly efficacious superagonist at GluN1/2C receptors (353\%). This clear subtypedependency of AICP is more pronounced compared with DCS, which is a partial agonist at GluN1/2A, GluN1/2B, and GluN1/2D (90\%, 63\%, and 76\%, respectively) and a superagonist at GluN1/2C receptors $(151 \%)$. Furthermore, the $\mathrm{EC}_{50}$ values of AICP between $1.7 \mathrm{nM}$ and $66 \mathrm{nM}$ at NMDA receptor subtypes make this agonist markedly more potent compared with DCS (3.1-22.0 $\mu \mathrm{M})$ and the endogenous agonists glycine and D-serine.

In addition to AICP and DCS, the function of GluN2Ccontaining NMDA receptors can be enhanced by the positive allosteric modulators (3-chlorophenyl)-[6,7-dimethoxy-1[(4-methoxyphenoxy)methyl]-3,4-dihydro- $1 H$-isoquinolin-2yl]methanone (CIQ) and pyrrolidinone analog (PYD-106) (Mullasseril et al., 2010; Khatri et al., 2014). CIQ enhances function of both diheteromeric and triheteromeric 
GluN2C/D-containing NMDA receptors and has been suggested to bind in or near the transmembrane region (Mullasseril et al., 2010; Ogden and Traynelis, 2013). By contrast, PYD-106 exhibits selectivity for diheteromeric GluN1/2C receptors with no effects on triheteromeric GluN1/2A/2C receptors and appears to bind at the interface between the agonist binding domain and ATD of GluN2C (Khatri et al., 2014). The different mechanisms of action and distinct binding sites for AICP/DCS compared with CIQ/PYD (i.e., agonists versus positive modulators) enable variation in activity among NMDA receptor subtypes, which is relevant to the utility of these ligands as tool compounds for in vivo biological studies. However, our identification of AICP as a GluN2C-selective superagonist expands the list of pharmacological tool compounds that can enhance the function of GluN2C-selective NMDA receptors and suggests that AICP may be helpful in studies that aim to uncover roles of GluN2C subunits in neuronal circuit function.

DCS can enhance extinction of fear in both rodents and humans (Walker et al., 2002; Ressler et al., 2004; Davis et al., 2006; Gupta et al., 2013), and this effect has been linked to its in vitro pharmacological profile among recombinant NMDA receptor subtypes (Hillman et al., 2011; Ogden et al., 2014). Administration of the GluN2C/D-selective positive allosteric modulator CIQ directly into the amygdala mimics the effects of DCS and increases both acquisition and extinction of conditioned fear responses (Ogden et al., 2014). These results suggest that modulation of conditioned fear responses by DCS is not mediated by its partial agonist activity at GluN2Bcontaining NMDA receptors but rather by its GluN2Cselective superagonist activity, which supports that activation of GluN2C-containing NMDA receptors in the amygdala is involved in acquisition and extinction of conditioned fear (Hillman et al., 2011; Ogden et al., 2014). In this regard, it remains to be shown whether the increased potency and efficacy of AICP at GluN2C-containing NMDA receptors will result in more pronounced modulation of conditioned fear responses compared with DCS.

We show that agonist efficacies of AICP and DCS are influenced by a nonconserved GluN2 residue located at the interface between GluN1 and GluN2 agonist binding domains (Glu790 in GluN2B and Gln800 in GluN2C). Furthermore, we show that agonist efficacies of AICP and DCS are also controlled by the GluN2 ATD, which displays considerable sequence variation among NMDA receptor subunits. These results suggest that the GluN2-dependent differences for AICP and DCS are mediated by structural mechanisms that involve multiple receptor domains.

Surprisingly, GluN2C-Q800E and GluN2B-E790Q mutations in the agonist binding domain produce opposing effects on AICP and DCS agonist efficacies, and differences thus exist in the mechanisms by which AICP and DCS are partial agonists at GluN1/2B and superagonists at GluN1/2C. It is possible that multiple mechanisms control GluN2-dependent variation in GluN1 agonist efficacy and that these mechanisms, which may be distinct or complementary, contribute differently to activation by AICP or DCS. For example, the GluN2 ATD could influence the interface between GluN1 and GluN2 agonist binding domains and thereby prohibit or enable interactions formed by Gln800 in GluN2C and Glu790 in GluN2B. Thus, the GluN2 ATD could modulate the propensity of nonconserved residues in the agonist binding domain dimer interface to influence GluN1 agonist efficacy.

Consistent with this idea, we demonstrate that AICP and DCS are not superagonists at GluN1/2A-(2C ATD) receptors, but that superagonist activity of AICP and DCS was completely removed at GluN1/2C-(2A ATD) receptors. That is, the GluN2C ATD is required for superagonistic activity of AICP and DCS, but superagonistic activity of GluN1 ligands also depends on additional structural elements in GluN2C. These findings highlight the need for more detailed functional and structural studies to discern the mechanisms that mediate variation in GluN1 agonist efficacy among NMDA receptor subtypes.

The unexpected and unique GluN2 subunit-dependent pharmacological profile of AICP demonstrates that GluN1 ligands can be designed with functional selectivity among the different NMDA receptor subtypes. This discovery creates a new avenue for subunit-selective modulation of NMDA receptors, which is considered an attractive strategy in the discovery of new treatments for a number of CNS disorders (Ogden and Traynelis, 2011; Paoletti et al., 2013; Strong et al., 2014). In addition, this discovery may inspire medicinal chemistry efforts to refine the pharmacological profiles of GluN1 glycine site agonists and to develop novel ligands that can be used as pharmacological tool compounds for uncovering the roles of the different GluN2 subunits in neuronal circuit function and behavior.

\section{Acknowledgments}

The authors thank Pia Maribo Sørensen (H. Lundbeck A/S), Annette Bjørn (H. Lundbeck A/S), and Gina Bullard (University of Montana) for excellent technical assistance, and Trine Kvist Carlino (University of Copenhagen) for kindly providing the mutant rat GluN1 constructs.

\section{Authorship Contributions}

Participated in research design: Jessen, Frederiksen, Yi, Clausen, Hansen, Bräuner-Osborne, Kilburn, Damholt.

Conducted experiments: Jessen, Frederiksen, Yi, Hansen. Performed data analysis: Jessen, Frederiksen, Yi, Hansen.

Wrote or contributed to the writing of the manuscript: Jessen, Frederiksen, Yi, Clausen, Hansen, Bräuner-Osborne, Kilburn, Damholt.

\section{References}

Balu DT and Coyle JT (2015) The NMDA receptor 'glycine modulatory site' in schizophrenia: D-serine, glycine, and beyond. Curr Opin Pharmacol 20:109-115.

Banke TG and Traynelis SF (2003) Activation of NR1/NR2B NMDA receptors. Nat Neurosci 6:144-152.

Benveniste M and Mayer ML (1991) Kinetic analysis of antagonist action at $N$ methyl-D-aspartic acid receptors. Two binding sites each for glutamate and glycine. Biophys J 59:560-573.

Bergeron R, Meyer TM, Coyle JT, and Greene RW (1998) Modulation of $N$-methyl-Daspartate receptor function by glycine transport. Proc Natl Acad Sci USA 95 15730-15734.

Billups D and Attwell D (2003) Active release of glycine or D-serine saturates the glycine site of NMDA receptors at the cerebellar mossy fibre to granule cell synapse. Eur J Neurosci 18:2975-2980.

Chen PE, Geballe MT, Katz E, Erreger K, Livesey MR, O’Toole KK, Le P, Lee CJ, Snyder JP, Traynelis SF, et al. (2008) Modulation of glycine potency in rat recombinant NMDA receptors containing chimeric NR2A/2D subunits expressed in Xenopus laevis oocytes. J Physiol 586:227-245.

Clements JD and Westbrook GL (1994) Kinetics of AP5 dissociation from NMDA receptors: evidence for two identical cooperative binding sites. J Neurophysiol $\mathbf{7 1}$ 2566-2569.

Davis M, Ressler K, Rothbaum BO, and Richardson R (2006) Effects of D-cycloserine on extinction: translation from preclinical to clinical work. Biol Psychiatry 60: 369-375.

Dravid SM, Burger PB, Prakash A, Geballe MT, Yadav R, Le P, Vellano K, Snyder JP, and Traynelis SF (2010) Structural determinants of D-cycloserine efficacy at the NR1/NR2C NMDA receptors. $J$ Neurosci 30:2741-2754. 
Dutta A, McKie S, and Deakin JF (2015) Ketamine and other potential glutamate antidepressants. Psychiatry Res 225:1-13.

Flood JF, Morley JE, and Lanthorn TH (1992) Effect on memory processing by D-cycloserine, an agonist of the NMDA/glycine receptor. Eur J Pharmacol 221: 249-254.

Gielen M, Siegler Retchless B, Mony L, Johnson JW, and Paoletti P (2009) Mechanism of differential control of NMDA receptor activity by NR2 subunits. Nature 459:703-707.

Goff DC (2015) Drug development in schizophrenia: are glutamatergic targets still worth aiming at? Curr Opin Psychiatry 28:207-215.

Gupta SC, Hillman BG, Prakash A, Ugale RR, Stairs DJ, and Dravid SM (2013) Effect of D-cycloserine in conjunction with fear extinction training on extracellular signal-regulated kinase activation in the medial prefrontal cortex and amygdala in rat. Eur J Neurosci 37:1811-1822.

Hansen KB, Tajima N, Risgaard R, Perszyk RE, Jørgensen L, Vance KM, Ogden KK, Clausen RP, Furukawa H, and Traynelis SF (2013) Structural determinants of agonist efficacy at the glutamate binding site of $N$-methyl-D-aspartate receptors. Mol Pharmacol 84:114-127.

Henderson G, Johnson JW, and Ascher P (1990) Competitive antagonists and partial agonists at the glycine modulatory site of the mouse $N$-methyl-D-aspartate receptor. J Physiol 430:189-212.

Hillman BG, Gupta SC, Stairs DJ, Buonanno A, and Dravid SM (2011) Behavioral analysis of NR2C knockout mouse reveals deficit in acquisition of conditioned fear and working memory. Neurobiol Learn Mem 95:404-414.

Hofmann SG, Otto MW, Pollack MH, and Smits JA (2015) D-Cycloserine augmentation of cognitive behavioral therapy for anxiety disorders: an update. Curr Psychiatry Rep 17:532.

Johnson JW and Ascher P (1992) Equilibrium and kinetic study of glycine action on the $N$-methyl-D-aspartate receptor in cultured mouse brain neurons. $J$ Physiol $\mathbf{4 5 5}$ : 339-365.

Karakas E and Furukawa H (2014) Crystal structure of a heterotetrameric NMDA receptor ion channel. Science 344:992-997.

Kenakin TP and Black JW (1978) The pharmacological classification of practolol and chloropractolol. Mol Pharmacol 14:607-623.

Khatri A, Burger PB, Swanger SA, Hansen KB, Zimmerman S, Karakas E, Liotta DC, Furukawa H, Snyder JP, and Traynelis SF (2014) Structural determinants and mechanism of action of a GluN2C-selective NMDA receptor positive allosteric modulator. Mol Pharmacol 86:548-560.

Kussius CL and Popescu GK (2009) Kinetic basis of partial agonism at NMDA receptors. Nat Neurosci 12:1114-1120.

Kvist T, Greenwood JR, Hansen KB, Traynelis SF, and Bräuner-Osborne H (2013) Structure-based discovery of antagonists for GluN3-containing $N$-methyl-D-aspartate receptors. Neuropharmacology 75:324-336.

Lench AM, Robson E, and Jones RS (2015) Differential effects of D-cycloserine and $\mathrm{ACBC}$ at NMDA receptors in the rat entorhinal cortex are related to efficacy at the co-agonist binding site. PLoS One 10:e133548.

McBain CJ, Kleckner NW, Wyrick S, and Dingledine R (1989) Structural requirements for activation of the glycine coagonist site of $N$-methyl-D-aspartate receptors expressed in Xenopus oocytes. Mol Pharmacol 36:556-565.

Menniti FS, Lindsley CW, Conn PJ, Pandit J, Zagouras P, and Volkmann RA (2013) Allosteric modulators for the treatment of schizophrenia: targeting glutamatergic networks. Curr Top Med Chem 13:26-54.

Monahan JB, Handelmann GE, Hood WF, and Cordi AA (1989) D-Cycloserine, a positive modulator of the $N$-methyl-D-aspartate receptor, enhances performance of learning tasks in rats. Pharmacol Biochem Behav 34:649-653.

Mullasseril P, Hansen KB, Vance KM, Ogden KK, Yuan H, Kurtkaya NL, Santangelo R, Orr AG, Le P, Vellano KM, et al. (2010) A subunit-selective potentiator of NR2Cand NR2D-containing NMDA receptors. Nat Commun 1:90.

Ogden KK, Khatri A, Traynelis SF, and Heldt SA (2014) Potentiation of GluN2C/D NMDA receptor subtypes in the amygdala facilitates the retention of fear and extinction learning in mice. Neuropsychopharmacology 39:625-637.

Ogden KK and Traynelis SF (2011) New advances in NMDA receptor pharmacology. Trends Pharmacol Sci 32:726-733.
Ogden KK and Traynelis SF (2013) Contribution of the M1 transmembrane helix and pre-M1 region to positive allosteric modulation and gating of $N$-methyl-D-aspartate receptors. Mol Pharmacol 83:1045-1056.

Otto MW, Kredlow MA, Smits JA, Hofmann SG, Tolin DF, de Kleine RA, van Minnen A, Evins AE, and Pollack MH (2016) Enhancement of psychosocial treatment with D-cycloserine: models, moderators, and future directions. Biol Psychiatry 80:274-283.

Paoletti P, Bellone C, and Zhou Q (2013) NMDA receptor subunit diversity: impact on receptor properties, synaptic plasticity and disease. Nat Rev Neurosci 14:383-400. Pérez-Otaño I, Larsen RS, and Wesseling JF (2016) Emerging roles of GluN3containing NMDA receptors in the CNS. Nat Rev Neurosci 17:623-635.

Priestley T and Kemp JA (1994) Kinetic study of the interactions between the glutamate and glycine recognition sites on the $N$-methyl-D-aspartic acid receptor complex. Mol Pharmacol 46:1191-1196.

Ressler KJ, Rothbaum BO, Tannenbaum L, Anderson P, Graap K, Zimand E, Hodges L, and Davis M (2004) Cognitive enhancers as adjuncts to psychotherapy: use of Dcycloserine in phobic individuals to facilitate extinction of fear. Arch Gen Psychiatry 61:1136-1144.

Schade S and Paulus W (2016) D-Cycloserine in neuropsychiatric diseases: a systematic review. Int $J$ Neuropsychopharmacol 19:pyv102.

Schuster GM and Schmidt WJ (1992) D-Cycloserine reverses the working memory impairment of hippocampal-lesioned rats in a spatial learning task. Eur $J$ Pharmacol 224:97-98.

Sheinin A, Shavit S, and Benveniste M (2001) Subunit specificity and mechanism of action of NMDA partial agonist D-cycloserine. Neuropharmacology 41:151-158.

Skolnick P, Popik P, and Trullas R (2009) Glutamate-based antidepressants: 20 years on. Trends Pharmacol Sci 30:563-569.

Strong KL, Jing Y, Prosser AR, Traynelis SF, and Liotta DC (2014) NMDA receptor modulators: an updated patent review (2013-2014). Expert Opin Ther Pat 24:1349-1366.

Szakacs R, Janka Z, and Kalman J (2012) The "blue" side of glutamatergic neurotransmission: NMDA receptor antagonists as possible novel therapeutics for major depression. Neuropsychopharmacol Hung 14:29-40.

Traynelis SF, Wollmuth LP, McBain CJ, Menniti FS, Vance KM, Ogden KK, Hansen KB, Yuan H, Myers SJ, and Dingledine R (2010) Glutamate receptor ion channels: structure, regulation, and function. Pharmacol Rev 62:405-496.

Urwyler S, Floersheim P, Roy BL, and Koller M (2009) Drug design, in vitro pharmacology, and structure-activity relationships of 3-acylamino-2-aminopropionic acid derivatives, a novel class of partial agonists at the glycine site on the $N$ methyl-D-aspartate (NMDA) receptor complex. J Med Chem 52:5093-5107.

Walker DL, Ressler KJ, Lu KT, and Davis M (2002) Facilitation of conditioned fear extinction by systemic administration or intra-amygdala infusions of D-cycloserine as assessed with fear-potentiated startle in rats. J Neurosci 22:2343-2351.

Watson GB, Bolanowski MA, Baganoff MP, Deppeler CL, and Lanthorn TH (1990) DCycloserine acts as a partial agonist at the glycine modulatory site of the NMDA receptor expressed in Xenopus oocytes. Brain Res 510:158-160.

Yang CR and Svensson KA (2008) Allosteric modulation of NMDA receptor via elevation of brain glycine and D-serine: the therapeutic potentials for schizophrenia Pharmacol Ther 120:317-332.

Yi F, Mou TC, Dorsett KN, Volkmann RA, Menniti FS, Sprang SR, and Hansen KB (2016) Structural basis for negative allosteric modulation of GluN2A-containing NMDA receptors. Neuron 91:1316-1329.

Yuan H, Hansen KB, Vance KM, Ogden KK, and Traynelis SF (2009) Control of NMDA receptor function by the NR2 subunit amino-terminal domain. $J$ Neurosci 29:12045-12058.

Zarate C, Duman RS, Liu G, Sartori S, Quiroz J, and Murck H (2013) New paradigms for treatment-resistant depression. Ann N Y Acad Sci 1292:21-31.

Address correspondence to: Dr. Kristen Frederiksen, Department of Molecular Screening, H. Lundbeck A/S, Ottiliavej 9, DK-2500 Valby, Denmark. E-mail: krf@lundbeck.com or Dr. Kasper B. Hansen, Department of Biomedical and Pharmaceutical Sciences, University of Montana, 32 Campus Dr, Missoula, Montana 59812. E-mail: kasper.hansen@mso.umt.edu 